practice, as regards duration and epoch of maturity, which are unknown to me, but which his much larger experience has brought under his notice, and in which the discrepant results referred to may arise. It would, however, appear that where the assurance matures either on a birthday or on a policy-anniversary, the combination of the nearest age at entry and the nearest duration will always give the age at maturity correctly, or to the nearest age.

\title{
Dupuicates.
}

Mr. Meikle also refers to the fact that, by the Nearest Duration Method, cases upon the same life may be recorded as both "existing" and terminating by death. This arises where the period of observation is closed on the policy-anniversary in a certain calendar year, so that, in the case of two or more assurances upon one life, the assured, if dying between the policy-anniversaries in the closing calendar year, would appear as "existing" under some of the assurances, and as "dead" under others.

'This difficulty appears, however, to arise solely from the limitations fixed in ascertaining the data, and not from the particular method of tabulation adopted.

I am, Sir,

Yours obediently,

THOMAS G. ACKLAND.

Croydon,

I June 1897.

\section{ON THE CALCULATIONS OF GEORGE BARRETT IN THE EARLY PART OF THIS CENTURY.}

To the Editor of the Journal of the Institute of Actuaries.

Sir,-Some calculations of George Barrett have recently passed through my hands, in my capacity as one of the Librarians of the Institute, containing some original details and notes which, I think, may be interesting to the readers of our Journal. The calculations have been placed at the disposal of the Institute by the London Life Association, through the kindness of Mr. C. D. Higham.

As is well known, Barrett introduced the use of Commutation Columns into England. Very little is known of him beyond the particulars given in a paper by De Morgan in vol. iv. of the Journal. In the rough calculations under notice, by far the greater part are folio sheets, covered both sides to the edges with figures, and as the final values are alternate with the subsidiary elements of the calculations, the arguments being very indistinct, no purpose would be served in having the sheets bound into volumes, as the Institute Library already possesses Barrett's Final Tables based on these calculations, hereafter referred to.

Barrett was assisted by his sister and a niece in the work, though everything was finally checked by himself and initialled. He does not appear to have been so happy in a male helper, as there is a remark at the foot of one page-" Note. The person whom I got 
" to finish this paper made a blundering job of it; he added instead " of subtracting."

Readers of the Text-Book will remember that Barrett's Commutation Columns, equivalent to our $\mathrm{D}$ and $\mathrm{N}$ columns, were marked $A$ and $B$, where $B_{x}=\Sigma A_{x}$. Barrett was in the habit of referring to them as Betsey and Nancy. There is a frequent reference, in brief directions to his assistants, to "Betsey's column and Nancy's first difference", and in one place, "those numbered with Black are the " sum of the last addition of Betsey's, and will therefore be a proof " of her additions being right if they agree." It may have been that Barrett's sister and niece were respectively named Betsey and Nancy, he naming the columns after them.

Barrett's great labour was a table of Commutation Columns for every possible combination of three joint lives, according to the Swedish 'Table of Observations (lives in general) at 4 per-cent.

The rough calculations present an enormous mass of figures on rough paper, evidently ruled by Barrett himself. The logs of the values of the $A$ column are formed by the method described in the appendix to the second volume of Baily's work on Annuities, p. 42. The logarithms were then transferred to a second set of sheets in the same order, and the antilogs entered under each value.

The second set occupies 410 folios foolscap.

There are some dates on this batch, the first being, "The first prime was finished by me 14th Oct. 1802, G. BarneTr." The first prime being all the combinations of ages having differences 0 to $n$, where $n$ had every value from 0 to 95 . On the last folio is written" Finis, G.B. Witness, Mrs. Purser, July 29 1804." With the very human addition, "When clock struck 6 in the evening"; also, "Finished transcribing the papers, Nov. 5th 1804, G. Barketr. "Finished re-examining the papers, June 11th 1806.

\section{"ANN-Nall BarretT, \\ "Geotrge Barrett."}

Referring in the list of tables to the table for three joint lives, Barrett says "although computed at a rate of interest 4 per-cent, it " can easily be made applicable to one of 3 or 5 per-cent by a " method of employing it, which is well known to those conversant "with the subject." A reliable method of easily making this transition would be a boon to Actuaries, but it does not appear that Barrett had in view any very exact method, for one of the Offices (the Provident), in answering his appeal for subscriptions, remarks that the approximation from his 4 per-cent Joint-Life Table to Northampton 3 per-cent, would be no more accurate than the methods in general use. It was a great pity that the Swedish Observations were used for this Table. Had the Northampton Table been used, the support offered by the Life Offices would, undoubtedly, have been much greater.

In Baily's paper there is a description of Barrett's device for forming the A column by means of movable slips having the values of $\lambda b x$ and $\lambda(1+i)^{n}$ written on them. Barrett calls them rods, and there are the two bundles which he brought up to London to show to Baily. It does not appear that he used this system very extensively, as there is a note on one folio that he gave up the idea of using the 
rods (on that particular table) as the resulting values were not so easily checked as when the table was formed in the usual manner. There are no papers which show that he used them for the three life table for which they were described as being specially applicable.

Barrett was very anxious to have the table so laboriously constructed, printed. It was out of the question for him to publish them at his own risk, and his attempt to get them published by subscription failed. He was never able to obtain enough names to warrant the commencement of the work of printing, and he refused Baily's suggestion to print part only of the tables.

The original draft of his prospectus is here with a blank dedication, afterwards filled in with the name of Lord Egremont, in whose service Barrett was a sort of steward.

This draft contains a paragraph stating his intention that "the "whole of them will, after the printing is completed, be deposited in "some public Institution in the Metropolis, not only for the benefit " of those who may be disposed to pursue the enquiry further, but "likewise for the purpose of correcting any error that may inadvertently "have occurred in the printing. A similar method has been adopted "with respect to some tables of logarithms, and is particularly "desirable in all large works of this kind."

Barrett, however, changed his mind as to the desirability of letting his manuscript go, and the paragraph did not appear in the prospectus as printed. The number of guineas the work was to cost is left blank in the draft.

Together with the draft of the prospectus are several sheets of solutions of various problems in life contingencies, intended to accompany the tables. There is an outline of a method for tabulating the data for forming a life table. The schedule shown is identical in form with one used by $\mathrm{Mr}$. Woolhouse for the Seventeen Offices Experience. The tables, as transcribed ready for printing, were bound up into six thick folio volumes, "handsomely bound", says Barrett. These volumes were presented to the Institute some time ago, also by the London Life Association.

Mr. Higham informs me that the Tables were purchased by the London Life Association on 6 July 1827, from Mr. Charles Babbage, for $\notin 150$, probably for reasons of public spirit. $\mathrm{Mr}$. Babbage to be allowed copies of De Parcieux's 'Tables for scientific purposes, but in case Mr. Babbage should connect himself with any Life Assurance Society, and be desirous of applying such Tables to the use of that Office, Mr. Babbage to pay to the Society the sum of $£ 50$ for the privilege of doing so.

$$
\text { I am, Sir, }
$$

Your obedient Servant,

FREDERICK SCHOOLING.

Prudential Assurance Company, 21 January 1897. 